areas where the granular and porous texture of the pebble has been exposed by removal of the surface; in some cases there are also parallel broken bands of extremely compact material, often with parallel striations running through them: the presence of these compact surfaces seems to be directly linked to the tools being used slowly or under great pressure.

There are two apparently valid criteria for assessing a tool's direction of movement. First, the compact areas are often 'scaly' at the edges or in the middle because of tiny superficial lacerations, and in the experimental engravings these scales were consistently raised in a direction opposite to that of the tool's trajectory. Second, the porous areas may be rippled or bear a succession of semicircular cavities with their convex surface facing the direction of movement. Similar scales and arcs occur in the abraded parallel grooves on pebbles used for retouching, again showing clearly the direction of movement.

At intersections of engraved lines it is often easy with a simple microscope or with plasticine imprints ${ }^{5}$ to see the order in which they were made. The scanning microscope makes this observation even more straightforward, as the later line removes any compact areas or striations in the earlier groove at the crossing point, whereas its own remain unbroken. In addition, the later groove often produces an irregular cavity at the intersection which also reveals the direction of its trajectory. In some cases, contact between two lines causes lateral slipping of the later groove at the crossing point, and the direction of the slip provides a further clue to the trajectory of the tool: the shift is downwards if the line is engraved from left to right, and to the left if the groove is made vertically downward.

The micromorphology of these incisions also reveals in which hand a tool was held: where an engraving is made from left to right by a right-handed person, the compact part of the abrasion occurs along the side of the groove that is closest to the experimenter. Where a right-hander makes a vertical groove downwards, the compact band occurs along its centre and left side.

D'Errico has produced definite criteria for identifying marks by the same tool: engraved lines are accompanied by minute secondary or 'parasite' striations caused by a partial, momentary contact between other parts of the tool with the pebble surface: the number, morphology and location of these fine marks constitute a unique "tool signature" ( $a$ in the figure). It has even been possible to see the point in an incision where slight breakage of the tool has occurred, and the line has continued with an increase in surface contact and a change in the morphology of the incision ${ }^{8}$. The secondary marks are particularly prevalent where lines are prolonged to a pebble's edge and the stone's curvature allows other parts of the tool to touch ( $c$ in the figure). Identical secondary striae in adjacent incisions imply the use of a single tool; because the striae are not a constant feature, but occur only where incisions were made in rapid succession, they allow the time when the engravings were made to be estimated.

D'Errico has compared these carefully documented observations with prehistoric specimens, mainly azilian pebbles from Rochedane, north-east France as well as specimens from other French sites. He looked at accurate resin replicas made by silicon elastomer impressions of their engraved surfaces in the microscope. $\mathrm{He}$ found the same marks at the starting points of lines, and found the same distinctive morphology at intersections, and the successions of semicircular cavities showing the direction of tool movement. On the other hand, compact areas are rare in the azilian lines and, where visible, have an altered surface clearly caused by postdepositional modification.

On those pebbles which have series of parallel engraved lines ( $d$ in the figure), the incisions were made from the centre to the edge, mostly from left to right by a right-hander. At the edges, the pattern of secondary striations was the same as that on the experimental specimens $(b$ in the figure) and revealed that adjacent incisions had probably been made in rapid succession by the same tool, probably as a single operation.

This observation certainly suggests that the series of marks studied by d'Errico were made rapidly and are not, therefore, slowly accumulated notations. However, the strongest claims for prehistoric lunar notations have been made for notches on bone $^{4}$, and it remains to be seen how far d'Errico's results are applicable to these; many of his morphological indicators appear similar to those described for butchering marks on bone ${ }^{10}$.

The extension of his method to purposeful incisions on organic materials will be the next stage of the debate. Although everyone agrees that notations may well have been made in prehistory, disagreement remains about whether their existence has yet been proved ${ }^{1-3}$.

Paul G. Bahn is a freelance writer on archaeology at 428 Anlaby Road. Hull HU3 6QP, UK.

d'Errico, F. Curr. Anth. 30, 117 (1989)

. Marshack, A. Curr. Anth. (in the press)

d'Errico. F. Curr. Anth. (in the press).

4. Marshack, A. The Roots of Civilization (Weidenfeld and Nicolson, London, 1972)

5. Bahn, P.G. \& Vertut, J. Images of the /ce Age (Windward, Leicester. 1988)

6. d'Errico, F. in Scanning Electron Microscopy in Archaeo logy (ed. Olsen, S.L.) 169 (Brit. Arch. Rep. Int. ser. 452 Oxford, 1988)

7. d'Errico, F. C.R. Acad. Sci. Paris 304, sér. II. 761 (1987) 8. d'Errico, F. L'Anthropologie 92, 101 (1988)

9. Thévenin, A. Gallia Préhistoire 26, 139 (1983)

10. Bromage. T.G. \& Boyde, A. Am. J. Phys. Anth. 65, 359 (1984).

\section{Wave travel}

OCEAN waves are an appealing and dramatic source of power. Rather surprisingly, their energy is essentially rotational. While the crests of the waves move forwards, their troughs move backwards, putting the water surface into closed elliptical trajectories. A stable shoreline is not needed to exploit these relative motions.

And so Daedalus is designing a wavepowered ship. It deploys a set of moveable paddles like stabilizers, which are extended into the local wave motion when it is moving with the ship, but retracted during its return flow. The ship thus ratchets over the sea on that component of the wave motion that coincides with its heading. Since a ship of fair size will span several wavelengths of the local swell, there will at any time be two or three wave elements around it with the desired motion. The wave thrust should therefore be fairly steady, and could be further smoothed and augmented by additional banks of paddles under the water, coupling into the deeper parts of the wave cycle. In principle, the 'paddleship' could achieve a reasonable fraction of the wave velocity itself perhaps ten or twenty knots in a lively sea.

Control is the big problem. Luckily an infrared wave-scanning device has already been developed to help ships cope with bad weather. This detects approaching waves so that a bank of transputers can calculate the best disposition of rudder and stabilizers to minimize their effect. With minor modifications, the same system could be adapted for the paddleship, calculating the paddle strategy that will extract most energy from each wave as it arrives. The ship will make its best headway directly into, or directly against, the waves; in a beam sea it may have to tack. It will steer by phasing the portside paddles against the starboard ones, making it wonderfully manoeuvrable: $180^{\circ}$ of phase shift will spin it about its own centre. Intriguingly, it will leave a calm wake behind it: a "waveshadow' region of depleted energy.

Such a simple vessel only needs a small crew; indeed, it could be completely computerized and unmanned. Tugs will tow a paddleship out to sea, and abandon it to its navigational program. Navigating by the global-positioning satellite transmissions, it will steer steadily to its destination, possibly with subtle detours to exploit vigorous sea conditions detected by satellite imagery and relayed to it from shore. Its radar will warn it of collisional hazards, which it will easily outmanoeuvre. In due course it will turn up at its destination to be captured by tugs and towed into port. The whole operation will be so cheap that, especially for stable commodity cargoes, its haphazard timetable will not matter. But it may face human hazards like stowaways and pirates.

David Jones

NATURE - VOL $339 \cdot 8$ JUNE 1989 